\title{
Catalytic decomposition of hydrogen peroxide and 4-chlorophenol in the presence of modified activated carbons
}

\author{
Hsu-Hui Huang a , Ming-Chun Lu ${ }^{\text {b,* }}$, Jong-Nan Chen ${ }^{a}$, Cheng-Te Lee ${ }^{a}$ \\ a Institute of Environmental Engineering, National Chiao Tung University, Hsinchu 300, Taiwan, ROC \\ ${ }^{\mathrm{b}}$ Department of Environmental Engineering and Health, Chia Nan University of Pharmacy and Science, Tainan 717, Taiwan, ROC
}

Received 14 May 2002; received in revised form 2 January 2003; accepted 2 January 2003

\begin{abstract}
The objective of this research was to examine the heterogeneous catalytic decomposition of $\mathrm{H}_{2} \mathrm{O}_{2}$ and 4-chlorophenol (4-CP) in the presence of activated carbons modified with chemical pretreatments. The decomposition of $\mathrm{H}_{2} \mathrm{O}_{2}$ was suppressed significantly by the change of surface properties including the decreased $\mathrm{pH}_{\mathrm{pzc}}$ modified with oxidizing agent and the reduced active sites occupied by the adsorption of 4-CP. The apparent reaction rate of $\mathrm{H}_{2} \mathrm{O}_{2}$ decomposition was dominated by the intrinsic reaction rates on the surface of activated carbon rather than the mass transfer rate of $\mathrm{H}_{2} \mathrm{O}_{2}$ to the solid surface. By the detection of chloride ion in suspension, the reduction of 4-CP was not only attributed to the advanced adsorption but also the degradation of 4-CP. The catalytic activity toward 4-CP for the activated carbon followed the inverse sequence of the activity toward $\mathrm{H}_{2} \mathrm{O}_{2}$, suggesting that acidic surface functional group could retard the $\mathrm{H}_{2} \mathrm{O}_{2}$ loss and reduce the effect of surface scavenging resulting in the increase of the 4-CP degradation efficiency. Few effective radicals were expected to react with 4-CP for the strong effect of surface scavenging, which could explain why the degradation rate of 4-CP observed in this study was so slow and the dechlorination efficiency was independent of the 4-CP concentration in aqueous phase. Results show that the combination of $\mathrm{H}_{2} \mathrm{O}_{2}$ and granular activated carbon (GAC) did increase the total removal of 4-CP than that by single GAC adsorption.

(C) 2003 Elsevier Science Ltd. All rights reserved.
\end{abstract}

Keywords: Granular activated carbon; Hydrogen peroxide; 4-Chlorophenol; Heterogeneous catalysis

\section{Introduction}

The application of Fenton-like chemical oxidation process for remediation of contaminated soils and treatment of wastewater has gained more attention in last decade (Ravikumar and Gurol, 1994; Kong et al., 1998; Lu et al., 2002). However the disadvantage of Fenton's reagent is that the homogeneous catalyst cannot be retained in the process thus causing additional water pollution. A number of researchers (Valentine and

\footnotetext{
${ }^{*}$ Corresponding author. Tel.: +886-6-2660489; fax: +886-6$2660489 / 2667323$.

E-mail address: mmclu@mail.chna.edu.tw (M.-C. Lu).
}

Wang, 1998; Miller and Valentine, 1999) with attempt to minimize the leaching of iron ion focused on the efficiency of heterogeneous catalysis for pollutant oxidation. Recently, considering the practical application of the oxidation process, supported iron oxides or granular size solid catalysts, such as graphite and activated carbon, were also studied for their catalytic characteristics (Lucking et al., 1998; Chou and Huang, 1999). In addition, the potential for applying $\mathrm{H}_{2} \mathrm{O}_{2}$ to Fenton-like water treatment is primarily restricted to the supply and stability of $\mathrm{H}_{2} \mathrm{O}_{2}$. Therefore, understanding the fate of $\mathrm{H}_{2} \mathrm{O}_{2}$ is still an important topic (Lin and Gurol, 1998; Huang et al., 2001).

Granular activated carbon (GAC), used as a catalyst as well as adsorbent in this study, has been applied for a 


\begin{tabular}{|c|c|c|c|}
\hline \multicolumn{4}{|c|}{ Nomenclature } \\
\hline$C_{\mathrm{H}}$ & $\mathrm{H}_{2} \mathrm{O}_{2}$ concentration in bulk solution $(\mathrm{mM})$ & $k_{\mathrm{H}}$ & equilibrium binding constant $\left(\mathrm{mM}^{-1}\right)$ \\
\hline DOC & dissolved organic carbon & $m$ & catalyst dosage $\left(\mathrm{g} / \mathrm{cm}^{3}\right)$ \\
\hline$d_{\mathrm{p}}$ & diameter of particle $(\mathrm{cm})$ & $\mathrm{pH}_{\mathrm{pzc}}$ & point of zero charge \\
\hline E & stoichiometric efficiency; $E_{\mathrm{R}}$ is the ratio for & $\mathrm{pH}_{\mathrm{f}}$ & $\mathrm{pH}$ at the end of reaction \\
\hline & 4-CP reduction (loss) to $\mathrm{H}_{2} \mathrm{O}_{2}$ decomposi- & $\underset{D}{Q}$ & adsorption capacity \\
\hline & $\begin{array}{l}\text { tion; } E_{\mathrm{D}} \text { is the ratio for } 4-\mathrm{CP} \text { dechlorination } \\
\text { to the } \mathrm{H}_{2} \mathrm{O}_{2} \text { decomposition }\end{array}$ & $R_{\mathrm{H}}$ & $\begin{array}{l}\text { decomposition rate of } \mathrm{H}_{2} \mathrm{O}_{2}(\mathrm{mM} / \mathrm{time}) ; R_{\mathrm{H}} \\
\text { for initial decomposition rate }\end{array}$ \\
\hline GAC & granular activated carbon & $\rho_{\mathrm{p}}$ & particle density $\left(\mathrm{g} / \mathrm{cm}^{3}\right)$ \\
\hline$k$ & rate constant & [] & concentration of solute in aqueous phase \\
\hline & mass transfer coefficient $(\mathrm{cm} / \mathrm{s})$ & & $(\mathrm{mM}) ;[]_{0}$ denotes initial concentration; \\
\hline$k_{\text {mass }}$ & $\begin{array}{l}\text { (observed rate constant)/(catalyst mass per } \\
\text { unit volume of solution) }\end{array}$ & & $\begin{array}{l}\mathrm{CP}]_{\mathrm{S}} \text { is } 4-\mathrm{CP} \text { concentration remaining in } \\
\text { solution after isotherm adsorption }\end{array}$ \\
\hline$k_{\text {suf }}$ & $\begin{array}{l}\text { (observed rate constant)/(catalyst total sur- } \\
\text { face area per unit volume of solution) }\end{array}$ & & \\
\hline
\end{tabular}

long time in the heterogeneous catalysis and adsorption for its enormous surface area, porous structure and characteristic flexibility (Francisco, 1998). A number of studies have been carried out on the interaction of oxidizing agents (e.g. $\mathrm{H}_{2} \mathrm{O}_{2}$ or $\mathrm{O}_{3}$ ) with carbon and carbonsupported materials (Heisig et al., 1997; Khalil et al., 2001). These investigations were not only concerned with the factors affecting the catalytic rate, but also directed toward applying this type of reaction for practical purposes, especially in environmental impacts. Recent studies (Lucking et al., 1998; Lin and Lai, 2000) indicated that surface catalyzed reaction of GAC induced by oxidizing agent may lead to contaminant decay in aqueous system. Although GAC adsorption method is effective to the removal of organic compounds, the GAC can get saturated easily in the process, which requires regeneration or complete replacement. Combination of both adsorption and heterogeneous catalysis into a single process could offer an attractive alternative in the wastewater treatment. Due to the complex role of GAC, the catalytic decomposition of $\mathrm{H}_{2} \mathrm{O}_{2}$ and contaminants with GAC deserves further investigation.

In this study, we examined and compared the surface catalyzed transformation of the model pollutant, 4chlorophenol (4-CP), by $\mathrm{H}_{2} \mathrm{O}_{2}$ in the presence of GAC with different surface properties modified by various chemical processes. The factors including $\mathrm{H}_{2} \mathrm{O}_{2}$ concentration, GAC dosage, and GAC types affecting the decomposition behavior of $\mathrm{H}_{2} \mathrm{O}_{2}$ and 4-CP are discussed.

\section{Material and methods}

The activated carbon was Filtrasorb-300 GAC supplied by the Calgon Carbon with an average particle density of $0.8 \mathrm{~g} / \mathrm{cm}^{3}$ and particle diameter of $0.64 \mathrm{~mm}$ (sieved with $20 \times 40$ US Mesh size). GAC1 was the original carbon which was washed several times with deionized water until most of the fines were removed. GAC2 and GAC3 were the products of GAC1 which was oxidized with concentrated $\mathrm{H}_{2} \mathrm{O}_{2}(1000 \mathrm{mg}$ GAC1 in $\left.10 \mathrm{ml}, 9.8 \mathrm{M} \mathrm{H}_{2} \mathrm{O}_{2}\right)$ and $\mathrm{HNO}_{3}(1000 \mathrm{mg} \mathrm{GACl}$ in $10 \mathrm{ml}, 13.9 \mathrm{~N} \mathrm{HNO}_{3}$ heated at $80{ }^{\circ} \mathrm{C}$ ) solution for $24 \mathrm{~h}$, respectively. Prior to the oxidation experiment, GAC1 and $\mathrm{GAC} 2$ were treated with diluted $\mathrm{HCl}$ solution (1000 $\mathrm{mg} \mathrm{GAC} \mathrm{in} 10 \mathrm{ml}, 1 \mathrm{~N} \mathrm{HCl}$ ) for $24 \mathrm{~h}$ to reduce the metal ions contained in GAC. After the treatment, all the activated carbons were washed with deionized water several times until the $\mathrm{pH}$ of the supernatant was constant. In addition, the GAC treated with diluted $\mathrm{HCl}$ was washed with boiling deionized water twice more to minimize the interference of chloride ions desorbed from GAC during the oxidation experiment. All GAC were dried in an oven at $50{ }^{\circ} \mathrm{C}$ for preservation. Specific surface area and average pore diameter were calculated by $\mathrm{N}_{2}$-BET meter (Micromeritics ASAP 2000). The value of $\mathrm{pH}_{\mathrm{pzc}}$ was measured by the mass titration method (Noh and Schwarz, 1989). Table 1 lists the properties of the activated carbons. The specific surface area increased slightly after the treatment with concentrated $\mathrm{H}_{2} \mathrm{O}_{2}$ but decreased significantly by the heating

Table 1

Characteristics of the activated carbons

\begin{tabular}{llll}
\hline Parameters & GAC1 & GAC2 & GAC3 \\
\hline Specific surface area $\left(\mathrm{m}^{2} / \mathrm{g}\right)$ & 983 & 1023 & 556 \\
Average pore size $(\AA)$ & 17.1 & 17.0 & 18.1 \\
Micropore volume $\left(\mathrm{cm}^{3} / \mathrm{g}\right)$ & 0.28 & 0.26 & 0.11 \\
$\mathrm{pH}_{\mathrm{pzc}}$ & $4.2^{\mathrm{a}}$ & $3.5^{\mathrm{a}}$ & 3.2 \\
\hline
\end{tabular}

${ }^{\mathrm{a}}$ After the treatment of diluted $\mathrm{HCl}$ and washing process. 
treatment of concentrated $\mathrm{HNO}_{3}$. This is due to the strong corrosive character of $\mathrm{HNO}_{3}$ which makes the pore walls thinner resulting in widening of the microporosity and consequently diminishing of the BET value. In addition, the general range of $\mathrm{pH}_{\mathrm{pzc}}$ for $\mathrm{F}-300$ is 9.8-10.2. Therefore, the washing and chemical treatment has affected the surface acidity of activated carbon significantly.

The experiments were conducted in $250 \mathrm{ml}$ flasks that were capped and shaken in a thermal oscillator tank at constant temperature of $30{ }^{\circ} \mathrm{C}$. The ionic strength was kept at $0.05 \mathrm{M}$ by the addition of $\mathrm{NaClO}_{4}$. The kinetics of $\mathrm{H}_{2} \mathrm{O}_{2}$ decomposition was studied by examining the variables such as the concentration of $\mathrm{H}_{2} \mathrm{O}_{2}$ and GAC. The reactor was prepared by filling proper amount of GAC and adjusted to the desired $\mathrm{pH}$ value several times (equilibrium for one day); the reaction mixture was 150 $\mathrm{ml}$; the reaction was initiated by the addition of $\mathrm{H}_{2} \mathrm{O}_{2}$. The range of the $\mathrm{pH}$ variance in the $\mathrm{H}_{2} \mathrm{O}_{2}$ decomposition experiment was less than unit. In the oxidation experiment of 4-CP, the reactor was prepared by introducing the proper amount of 4-CP and GAC; the reaction mixture was $200 \mathrm{ml}$. The adsorption equilibrium of the solution (GAC and 4-CP) was to be achieved for at last three days prior to the oxidation experiment. Samples taken from the reactor within certain time intervals were filtered through $0.45 \mu \mathrm{m}$ membrane filters to separate GAC particles from the solution. $\mathrm{H}_{2} \mathrm{O}_{2}$ concentration was quantified by the peroxytitanic acid method with the addition of $\mathrm{Ti}\left(\mathrm{SO}_{4}\right)_{2}$ test solution (Schumb et al., 1955). Residual 4-CP was measured by an HPLC (Water LC module 1) with a reverse phase $3.9 \times 150 \mathrm{~mm}$ Nova-Pak $\mathrm{C}_{18}$ column (Waters). Total dissolved organic carbon (DOC) was determined using a TOC analyzer (Shimadzu 5000A). Concentration of chloride ion was measured with a chloride analyzer (Cole-Parmer U27502-13 plus WTW pH340/ion meter).

\section{Results and discussion}

\subsection{Hydrogen peroxide decomposition}

\subsubsection{Comparison of modified activated carbons}

The decomposition of $\mathrm{H}_{2} \mathrm{O}_{2}$ with GAC in the presence and absence of 4-CP is shown in Fig. 1. The reaction behavior followed a first-order rate expression with respect to $\mathrm{H}_{2} \mathrm{O}_{2}$ concentration, which is consistent with the observation of the previous research (Khalil et al., 2001). The decomposition of $\mathrm{H}_{2} \mathrm{O}_{2}$ with the activated carbon of which surface has been saturated with 4-CP in advance is still found to follow a first-order reaction. However, the decomposition rate was reduced largely in comparison with that in the absence of 4-CP. This is attributed to the 4-CP adsorption which reduces the surface active sites available for the $\mathrm{H}_{2} \mathrm{O}_{2}$. Lucking et al.
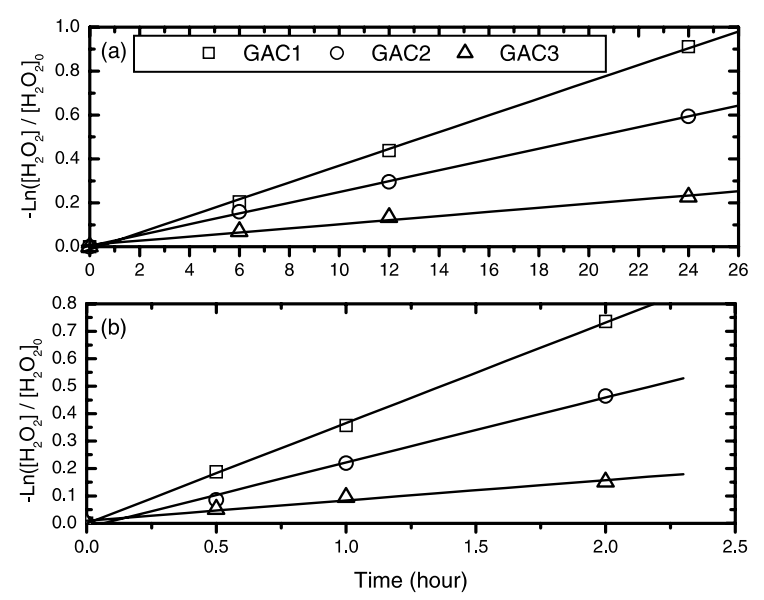

Fig. 1. Change of $\mathrm{H}_{2} \mathrm{O}_{2}$ concentration in presence and absence of 4-CP (a) $500 \mathrm{mg} / \mathrm{l} \mathrm{GAC}$ with addition of 4-CP; (b) $1000 \mathrm{mg} / \mathrm{l}$ GAC without 4-CP $\left(\left[\mathrm{H}_{2} \mathrm{O}_{2}\right]_{0}, 20 \mathrm{mM}\right.$; temperature, $30{ }^{\circ} \mathrm{C}$; ionic strength, $50 \mathrm{mM} \mathrm{NaClO}$ ).

(1998) reported the similar results in their adsorption/ oxidation system using GAC as catalyst. But, slight influence of organics adsorption on $\mathrm{H}_{2} \mathrm{O}_{2}$ decomposition was observed in the previous researches using iron oxide as catalyst. Those were due to the low affinity of organics with the metal oxide surface (Valentine and Wang, 1998; Huang et al., 2001).

A comparison of catalytic activity toward $\mathrm{H}_{2} \mathrm{O}_{2}$ decomposition for the activated carbons is shown in Table 2 . The $k_{\text {mass }}$ and $k_{\text {suf }}$ are the first-order decomposition rate coefficients modified on the basis of the mass and total surface area of catalyst per unit volume of reaction mixture, respectively (Valentine and Wang, 1998). Apparently, no matter the observed rate constant is modified with mass or surface area basis, the catalytic activity toward $\mathrm{H}_{2} \mathrm{O}_{2}$ decomposition is the highest for GAC1 and the least for GAC3 either in the presence or absence of 4-CP. In the majority of previous studies, $\mathrm{H}_{2} \mathrm{O}_{2}$ decomposition with activated carbon is considered to depend mainly on carbon porosity, slurry $\mathrm{pH}$, and chemical properties of the surface (Khalil et al., 2001). Regarding the effect of porosity on the extent of $\mathrm{H}_{2} \mathrm{O}_{2}$ decomposition, the difference of micropore volume and pore size between GAC1 and GAC2 (Table 1) is insignificant; moreover, the effect of pore diffusion (i.e. reaction rate reduced by pore diffusion) for GAC3 with larger pore size is expected to be less than those for GAC1 and GAC2. This indicates that the effect of porosity on $\mathrm{H}_{2} \mathrm{O}_{2}$ decomposition for the three activated carbons is not the major factor. Although the $\mathrm{H}_{2} \mathrm{O}_{2}$ decomposition is dependent generally on the $\mathrm{pH}$ of the carbon slurry, the values of $\mathrm{pH}_{\mathrm{f}}, \mathrm{pH}$ at the end of the reaction, for the reaction mixtures containing $\mathrm{GACl}$ and GAC2 were controlled at the similar range from 6.8 to 7.2. This signifies that the variance of rate constant in 
Table 2

The rate constant of $k_{\text {mass }}, k_{\text {suf }}$ in the presence and absence of 4-CP

\begin{tabular}{llllll}
\hline Catalyst type & $k_{\text {mass }}{ }^{\mathrm{a}}$ & $k_{\text {suf }}{ }^{\mathrm{a}}$ & $\mathrm{pH}_{\mathrm{f}}{ }^{\mathrm{a}}$ & $k_{\text {mass }}{ }^{\mathrm{b}}$ & $\mathrm{pH}_{\mathrm{f}}{ }^{\mathrm{b}}$ \\
\hline GAC1 & $6.71 \times 10^{-6}$ & $6.83 \times 10^{-6}$ & $\sim 7.0^{\mathrm{c}}$ & $1.27 \times 10^{-3}$ & $\sim 4.5$ \\
GAC2 & $4.87 \times 10^{-6}$ & $4.76 \times 10^{-6}$ & $\sim 7.0^{\mathrm{c}}$ & $8.21 \times 10^{-4}$ & $\sim 4.3$ \\
GAC3 & $1.17 \times 10^{-6}$ & $2.12 \times 10^{-6}$ & $\sim 3.9$ & $3.33 \times 10^{-4}$ & $\sim 3.5$ \\
\hline
\end{tabular}

$k_{\text {mass }}: \min ^{-1}(\mathrm{mg} / \mathrm{l})^{-1} ; k_{\text {suf }}: \min ^{-1}\left(\mathrm{~m}^{2} / 1\right)^{-1}$.

${ }^{a}$ In the absence of 4-CP.

${ }^{\mathrm{b}}$ In the presence of 4-CP; $\left[\mathrm{H}_{2} \mathrm{O}_{2}\right]_{0}=20 \mathrm{mM}$; catalyst dosage $=1000 \mathrm{mg} / \mathrm{l}$.

${ }^{\mathrm{c}}$ With $\mathrm{pH}$ control; $\left[\mathrm{H}_{2} \mathrm{O}_{2}\right]_{0}=5 \mathrm{mM}$; catalyst dosage $=500 \mathrm{mg} / \mathrm{l}$.

such an oxidation system is attributed not only to the medium $\mathrm{pH}$ but also the surface characteristic of GAC. Additional experiments without $\mathrm{pH}$ adjustment also show the same decline trend of catalytic activity toward $\mathrm{H}_{2} \mathrm{O}_{2}$ decomposition with the decreased $\mathrm{pH}_{\mathrm{pzc}}$ of the activated carbons. It was reported that acidic oxygen surface complexes (e.g. carboxylic, phenolic, and lactonic groups) would be introduced predominantly onto activated carbons when they were treated with oxidizing agents such as $\mathrm{H}_{2} \mathrm{O}_{2}$ and $\mathrm{HNO}_{3}$ (Castilla et al., 1995; Figueiredo et al., 1999). Therefore, the lower $\mathrm{pH}_{\mathrm{pzc}}$ of the modified activated carbon shown in Table 1 is probably due to the formation of acidic function groups on the surface.

It has been widely suggested that catalytic decomposition of $\mathrm{H}_{2} \mathrm{O}_{2}$ by activated carbon could be initiated by the exchange of a hydroxyl group with a hydrogen peroxide anion as shown below (Khalil et al., 2001),

$$
\begin{aligned}
& \text { Carbon-surface) } \mathrm{C} \frac{\mathrm{H}^{+}}{\mathrm{H}} \mathrm{O} \cdots \mathrm{OH}^{-}+\mathrm{H}^{+} \mathrm{OOH}^{-} \\
& \rightarrow \mathrm{C} \frac{\mathrm{H}^{+}}{\mathrm{H}} \mathrm{O} \cdots \mathrm{OOH}^{-}+\mathrm{H}_{2} \mathrm{O}
\end{aligned}
$$

$\mathrm{H}_{2} \mathrm{O}_{2}$, meanwhile, can be thought as a weak acid $\left(\mathrm{p} K_{\mathrm{a}}=11.6\right)$ to proceed its dissociation to $\mathrm{H}^{+}$and $\mathrm{OOH}^{-}$. The $\mathrm{OOH}^{-}$anion, much less stable than $\mathrm{H}_{2} \mathrm{O}_{2}$ itself, decomposed readily. From the assumptions, it is reasonable to predict that the dissociation of $\mathrm{H}_{2} \mathrm{O}_{2}$ will be enhanced in alkaline medium. As the result, the acidic function groups of GAC2 and GAC3 treated with $\mathrm{H}_{2} \mathrm{O}_{2}$ and $\mathrm{HNO}_{3}$ would retard the combination and dissociation of $\mathrm{H}_{2} \mathrm{O}_{2}$ resulting in suppressing the $\mathrm{H}_{2} \mathrm{O}_{2}$ decomposition rate considerably. Our results confirm again that the surface chemical nature of the GAC modified with oxidizing agent is the major factor in governing the catalytic action of $\mathrm{GAC}$ on $\mathrm{H}_{2} \mathrm{O}_{2}$ decomposition.

\subsubsection{Decomposition kinetics}

The decomposition behavior was clarified with the consideration of the effect of $\mathrm{H}_{2} \mathrm{O}_{2}$ concentration and catalyst dosage. Consistent with general observation on the heterogeneous catalytic decomposition of $\mathrm{H}_{2} \mathrm{O}_{2}$ ( $\mathrm{Lin}$ and Gurol, 1998; Huang et al., 2001), the experiments conducted with various catalyst dosages establish a linear relationship between the observed first-order rate constant and the mass of activated carbon. However, the observed rate constants of $\mathrm{H}_{2} \mathrm{O}_{2}$ decomposition conducted with various initial $\mathrm{H}_{2} \mathrm{O}_{2}$ concentrations $\left(\left[\mathrm{H}_{2} \mathrm{O}_{2}\right]_{0}\right.$ : from 4 to $\left.30 \mathrm{mM}\right)$ in the presence of GAC were found to decline with the increasing $\left[\mathrm{H}_{2} \mathrm{O}_{2}\right]_{0}$. The phenomenon seems different from other studies using metal oxides as the catalyst (Lin and Gurol, 1998; Huang et al., 2001) in which observed rate constant was independent of the $\left[\mathrm{H}_{2} \mathrm{O}_{2}\right]_{0}$. To analyze the catalytic kinetics of $\mathrm{H}_{2} \mathrm{O}_{2}$ decomposition, a modified LangmuirHinshelwood $(\mathrm{L}-\mathrm{H})$ rate model with the consideration of catalyst dosage is used to approach the experimental data conducted with various $\left[\mathrm{H}_{2} \mathrm{O}_{2}\right]_{0}$. The rate model is described as

$R_{\mathrm{H}}=-\frac{\mathrm{d}\left[\mathrm{H}_{2} \mathrm{O}_{2}\right]}{\mathrm{d} t}=\frac{k[\text { catalyst }]\left[\mathrm{H}_{2} \mathrm{O}_{2}\right]}{1+k_{\mathrm{H}}\left[\mathrm{H}_{2} \mathrm{O}_{2}\right]}$

where $k_{\mathrm{H}}$ and $k$ are the binding and rate constant, respectively. The inverse initial decomposition rate of $\mathrm{H}_{2} \mathrm{O}_{2}\left(R_{\mathrm{Hi}}\right)$ versus $\left[\mathrm{H}_{2} \mathrm{O}_{2}\right]_{0}$ is plotted in Fig. 2. In this

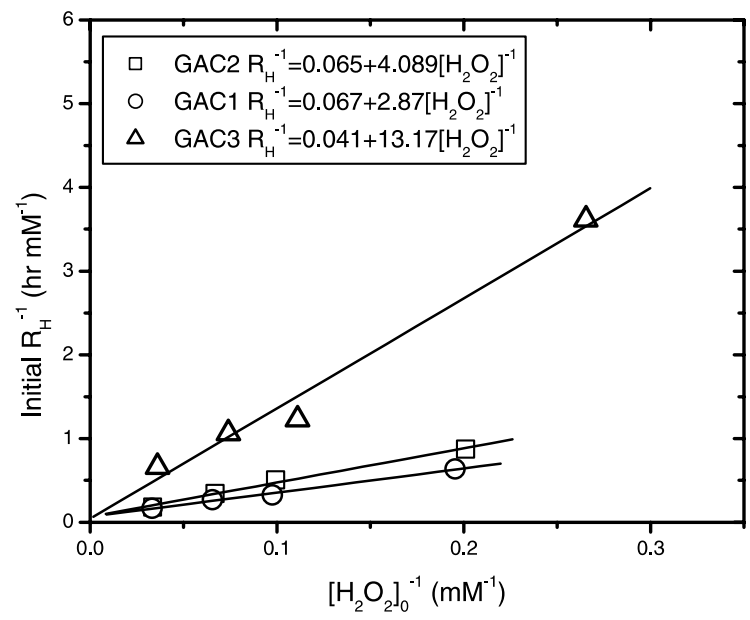

Fig. 2. Reciprocal of initial rate versus reciprocal of initial $\mathrm{H}_{2} \mathrm{O}_{2}$ concentration (GAC, $1000 \mathrm{mg} / \mathrm{l}$; temperature, $30{ }^{\circ} \mathrm{C}$; ionic strength, $50 \mathrm{mM} \mathrm{NaClO}_{4}$ ). 
Table 3

The parameters of $k$ and $k_{\mathrm{H}}$ in L-H model

\begin{tabular}{llll}
\hline Catalyst type & $k\left(\mathrm{~min}^{-1}\right)$ & $k_{\mathrm{H}}\left(\mathrm{mM}^{-1}\right)$ & $\mathrm{pH}_{\mathrm{f}}$ \\
\hline GAC1 $^{\mathrm{a}}$ & $5.93 \times 10^{-3}$ & $2.33 \times 10^{-2}$ & $\sim 7.0$ \\
$\mathrm{GAC2}^{\mathrm{a}}$ & $4.11 \times 10^{-3}$ & $1.71 \times 10^{-2}$ & $\sim 7.0$ \\
$\mathrm{GAC} 3$ & $1.25 \times 10^{-3}$ & $0.31 \times 10^{-2}$ & $\sim 3.9$ \\
\hline
\end{tabular}

${ }^{\mathrm{a}}$ With $\mathrm{pH}$ control; $\left[\mathrm{H}_{2} \mathrm{O}_{2}\right]_{0}=4-30 \mathrm{mM}$; catalyst dosage $=$ $1000 \mathrm{mg} / \mathrm{l}$.

figure, the reciprocal of the $R_{\mathrm{Hi}}$ is directly proportional to the reciprocal of the $\left[\mathrm{H}_{2} \mathrm{O}_{2}\right]_{0}\left(R^{2}>0.98\right)$. Hence, it can be concluded that the reaction behavior of $\mathrm{H}_{2} \mathrm{O}_{2}$ decomposition with the GAC can be well described by the modified $\mathrm{L}-\mathrm{H}$ model. $\mathrm{L}-\mathrm{H}$ kinetic rate model has been used empirically to describe many heterogeneous catalytic surface reactions (Lin and Gurol, 1998). From the intercept and the slope of the regression line, the initial rate constant $k$ and binding constant $k_{\mathrm{H}}$ are listed in Table 3. The rate constants obtained from the $\mathrm{L}-\mathrm{H}$ model are found to be a little less than but still similar to the values of $k_{\text {mass }}$ shown in Table 2, indicating that the rate model could be simplified as a second-order rate expression with respect to the $\mathrm{H}_{2} \mathrm{O}_{2}$ concentration and catalyst dosage when the products of $k_{\mathrm{H}}$ and $\left[\mathrm{H}_{2} \mathrm{O}_{2}\right]$ in the denominator are much smaller than unity. In addition, the binding constant $k_{\mathrm{H}}$ also follows the increased sequence of the catalytic activity for the activated carbons, implying the catalytic activity is dependent on the accessibility between the surface function groups and reactants. From the above discussion, it seems plausible that the surface phenomenon rather than mass transfer is the major factor, and the surface reaction is likely to control the overall reaction rate for the heterogeneous decomposition of $\mathrm{H}_{2} \mathrm{O}_{2}$ with GAC. In general, the apparent rate of a heterogeneous reaction is dominated by either the rate of intrinsic reaction on the surface or the diffusion rate of the reactant to the surface. The comparison of total molar flux can be used as a simple method to determine whether the film resistance or the surface reaction is the rate-controlling step. The maximum observed rate constant toward $\mathrm{H}_{2} \mathrm{O}_{2}$ decomposition for GAC1 is obtained as $1.19 \times 10^{-4} \mathrm{~s}^{-1}$. Hence, the product (i.e. $R_{\mathrm{H}}$ ) of maximum rate constant and $\mathrm{H}_{2} \mathrm{O}_{2}$ concentration (e.g. $5 \mathrm{mM}$ ) is $5.95 \times 10^{-4} \mathrm{mM} \mathrm{s}^{-1}$. If the overall reaction rate were completely controlled by mass transfer, the surface concentration of the reactant would approach zero and the observed reaction rate could be calculated by the simplified rate equation (Satterfield, 1981)

$R_{\mathrm{H}}=\frac{6 m k_{\mathrm{c}} C_{\mathrm{H}}}{\rho_{\mathrm{p}} d_{\mathrm{p}}}$

where $k_{\mathrm{c}}$ is mass transfer coefficient and can be estimated as $0.01 \mathrm{~cm} / \mathrm{s}$ which is a typical value in agitated water system, $m$ is the catalyst dosage $\left(\mathrm{g} / \mathrm{cm}^{3}\right), \rho_{\mathrm{p}}$ is the particle density, and $d_{\mathrm{p}}$ is the particle diameter. Therefore, the observed rate estimated by Eq. (3) with the same $\mathrm{H}_{2} \mathrm{O}_{2}$ concentration $\left(\mathrm{C}_{\mathrm{H}}=5 \mathrm{mM}\right)$ for $\mathrm{GACl}$ is $5.8 \times 10^{-3}$ $\mathrm{mM} \mathrm{s}^{-1}$. This is about 10 times the fastest rate observed in our experiment, indicating that the $\mathrm{H}_{2} \mathrm{O}_{2}$ concentration gradient between bulk liquid and catalyst outside surface, i.e. film resistance, could be neglected in this system. As the result, it is concluded that the catalytic reaction of $\mathrm{H}_{2} \mathrm{O}_{2}$ decomposition follows the $\mathrm{L}-\mathrm{H}$ rate model; meanwhile, surface reaction is the rate-controlling step for the overall catalytic reaction.

\subsection{Chlorophenol oxidation}

\subsubsection{Comparison of modified activated carbons}

The decomposition of $\mathrm{H}_{2} \mathrm{O}_{2}$ could be described with a simple first-order rate expression either in the absence or in the presence of organics over the GAC. The experiment of 4-CP oxidation was conducted with the modified GAC. To exclude the competing adsorption of 4-CP which makes it difficult to differentiate the effect of adsorption and heterogeneous catalysis on the removal of 4-CP, the adsorption equilibrium of the solution is required prior to the oxidation experiment. The adsorption capacity of GAC obtained from the adsorption isotherm is listed in Table 4, indicating that the adsorption property of GAC is affected by the modified surface property. Acidic oxygen-containing surface functional groups were found to affect the adsorptive properties of activated carbons, and decrease the chemisorption of phenols (Tessmer et al., 1997).

Based on the mechanisms for the catalytic oxidation of contaminant by $\mathrm{H}_{2} \mathrm{O}_{2}$ proposed in the literatures (Miller and Valentine, 1995; Valentine and Wang, 1998), the oxidation loss of model pollutant, 4-CP, could be hypothesized to be proportional to the decomposition amount of $\mathrm{H}_{2} \mathrm{O}_{2}$. The stoichiometric efficiencies, $E_{\mathrm{R}}$ and $E_{\mathrm{D}}$, are defined individually as the ratios of the reduction and dechlorination amount of 4-CP to the decomposition amount of $\mathrm{H}_{2} \mathrm{O}_{2}$.

$E_{\mathrm{R}}=\frac{\Delta[4-\mathrm{CP}]_{\mathrm{R}}}{\Delta\left[\mathrm{H}_{2} \mathrm{O}_{2}\right]} \quad$ and $\quad E_{\mathrm{D}}=\frac{\Delta[4-\mathrm{CP}]_{\mathrm{D}}}{\Delta\left[\mathrm{H}_{2} \mathrm{O}_{2}\right]}$

where the $\Delta[4-\mathrm{CP}]_{\mathrm{R}}$ and $\Delta[4-\mathrm{CP}]_{\mathrm{D}}$ are the amount of 4CP lost which are detected by HPLC and chloride analyzer, respectively. It should be emphasized that the term, reduction, in this study represents the loss of 4-CP attributed to the degradation and advanced adsorption (if occurred) of 4-CP during oxidation experiment.

The results of the preliminary experiments conducted with different $\mathrm{H}_{2} \mathrm{O}_{2}$ concentrations in the presence of GAC revealed a general trend that the degradation of 4$\mathrm{CP}$ increased with the increase of $\mathrm{H}_{2} \mathrm{O}_{2}$ concentration (data not shown here). The values of catalytic efficiencies 
Table 4

The effect of modified activated carbons on the adsorption capacity and removal efficiency toward 4-CP

\begin{tabular}{lllll}
\hline & & GAC1 & GAC2 & GAC3 \\
\hline Adsorption $_{\text {capacity }^{\mathrm{a}}}$ & $Q(\mathrm{mmol} / \mathrm{g})$ & 1.66 & 1.61 & 0.77 \\
Reduction $^{\mathrm{b}}$ & $\mathrm{pH}_{\mathrm{f}}$ & 5.7 & 4.7 & 3.8 \\
& $E_{\mathrm{R}}(\mathrm{mmol} / \mathrm{mmol})$ & $0.49 \times 10^{-2}$ & $0.63 \times 10^{-2}$ & $0.28 \times 10^{-1}$ \\
& $E_{\mathrm{D}}(\mathrm{mmol} / \mathrm{mmol})$ & $0.41 \times 10^{-2}$ & $0.37 \times 10^{-2}$ & $0.12 \times 10^{-1}$ \\
& $\mathrm{pH}_{\mathrm{f}}$ & 5.2 & 4.3 & 3.6 \\
\hline
\end{tabular}

${ }^{\mathrm{a}}$ Adsorption isotherm for $72 \mathrm{~h},[4-\mathrm{CP}]_{0}=1.13 \mathrm{mM}$; catalyst dosage $=500 \mathrm{mg} / 1 ; 30^{\circ} \mathrm{C}$.

${ }^{\mathrm{b}}$ Catalytic oxidation for $24 \mathrm{~h},\left[\mathrm{H}_{2} \mathrm{O}_{2}\right]_{0}=20 \mathrm{mM}$; catalyst dosage $=500 \mathrm{mg} / \mathrm{l} ; 30^{\circ} \mathrm{C}$.

for the three activated carbons with the addition of 20 $\mathrm{mM} \mathrm{H}_{2} \mathrm{O}_{2}$ are shown in Table 4. GAC3 shows the highest catalytic efficiency either in terms of reduction and dechlorination. However, the highest catalytic ability toward $\mathrm{H}_{2} \mathrm{O}_{2}$ decomposition for GACl cannot induce a relative high loss of 4-CP, resulting in a lower value of catalytic efficiency. Therefore, not only the adsorption capacity but also the catalytic efficiency of 4$\mathrm{CP}$ would be affected significantly by the modification of GAC. The reduction and dechlorination efficiency for GAC3 is 0.028 and 0.012 (mol/mol). This offers a comparable efficiency to those obtained from the other heterogeneous oxidation systems using metal oxides as catalyst. The majority of the stoichiometric efficiency reported earlier for catalytic oxidation of organics by $\mathrm{H}_{2} \mathrm{O}_{2}$ with iron oxide fell in the range of $10^{-2} \sim 10^{-4}$ (mol/mol) (Huang et al., 2001).

In addition, the loss of 4-CP could involve both heterogeneous and homogeneous catalytic reactions. Lucking et al. (1998) investigated the catalytic role of various activated carbons, certain amount of dissolved iron ion was observed to enhance the oxidation rate of 4-CP in the reaction volume during the oxidation experiment. To determine the importance of homogeneous reaction, the filtrate samples were aged for $24 \mathrm{~h}$ and the 4-CP concentration was monitored. No significant homogeneous loss was observed, which is attributed to the pretreatment of the GAC by strong acidic solution.

\subsubsection{Sequential oxidation process}

To further clarify the relative reactivity of each modified GAC, three sequential dosages of $\mathrm{H}_{2} \mathrm{O}_{2}$ were added into the reaction suspensions. The reduction of 4$\mathrm{CP}$ and $\mathrm{H}_{2} \mathrm{O}_{2}$ concentration in the presence of GAC is shown in Fig. 3. It should be noted that the starting concentration of $4-\mathrm{CP},[4-\mathrm{CP}]_{\mathrm{s}}$, represents the $4-\mathrm{CP}$ concentration remaining in the solution after the isotherm adsorption experiment. The effect of starting 4-CP concentration on catalytic efficiency will be discussed later. The overall reduction of 4-CP is obviously higher than that with the single dosage of $\mathrm{H}_{2} \mathrm{O}_{2}$, indicating that the loss of 4-CP increases with the increase of $\mathrm{H}_{2} \mathrm{O}_{2}$ decomposition. This is coincident with the hypothesis suggested by Miller and Valentine (1995) mentioned

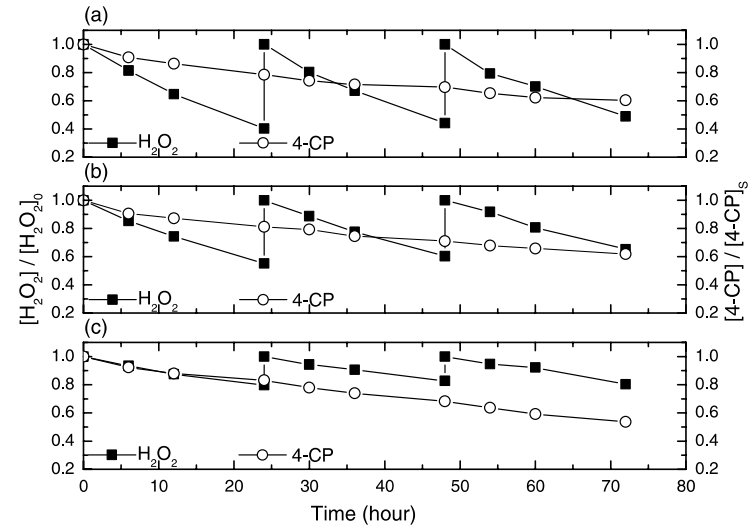

Fig. 3. Change of 4-CP and $\mathrm{H}_{2} \mathrm{O}_{2}$ concentrations with three sequential additions of $20 \mathrm{mM} \mathrm{H}_{2} \mathrm{O}_{2}$ in presence of activated carbons (GAC, $500 \mathrm{mg} / 1 ;\left[\mathrm{H}_{2} \mathrm{O}_{2}\right]_{0}, 20 \mathrm{mM}$; temperature, $30{ }^{\circ} \mathrm{C}$; ionic strength, $50 \mathrm{mM} \mathrm{NaClO}$ ).

earlier. It is shown that the higher reduction of $52 \%$ occurred with GAC3, and similar loss of $40 \%$ occurred in the presence of GAC1 and GAC2. However, an inverse trend of $\mathrm{H}_{2} \mathrm{O}_{2}$ decomposition is observed; the smallest loss of $\mathrm{H}_{2} \mathrm{O}_{2}$ for GAC3, a medium loss for GAC2, and the largest decomposition of $\mathrm{H}_{2} \mathrm{O}_{2}$ occurred with GAC1. As the result, the surface characteristic of activated carbons could be considered as the major factor affecting the 4-CP degradation as well as the $\mathrm{H}_{2} \mathrm{O}_{2}$ decomposition discussed earlier. Fig. 4 shows the accumulative reduction and dechlorination of 4-CP as the function of $\mathrm{H}_{2} \mathrm{O}_{2}$ decomposition for the sequential $\mathrm{H}_{2} \mathrm{O}_{2}$ dosage in the presence of GAC. The trend of dechlorination of 4-CP is observed being similar to that of reduction but the efficiency of dechlorination (i.e. $E_{\mathrm{D}}$ ) is general one-third of that of reduction (i.e. $E_{\mathrm{R}}$ ). This phenomenon could be attributed to the uptake of chloride ion which decreases the real dechlorination amount of 4-CP. Chloride ion could form an outer-sphere complex outside the surface of the metal oxide (Stumm, 1992). As the result, the detection of chloride ion can not represent the total degradation of 4-CP. Nevertheless, it is apparent that the real catalytic efficiency of 4-CP falls in the range between the observed values of reduction and dechlorination. 

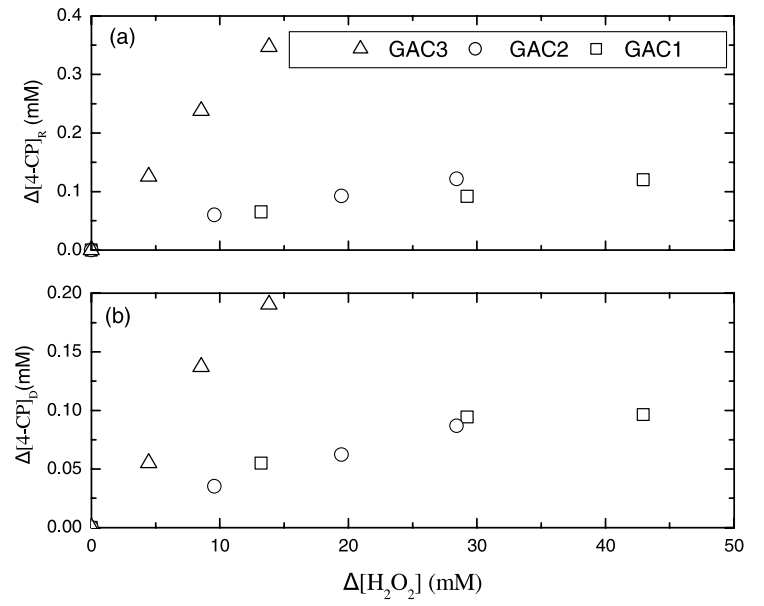

Fig. 4. Relationship between loss of 4-CP and decomposition of $\mathrm{H}_{2} \mathrm{O}_{2}$ in presence of activated carbons (a) reduction; (b) dechlorination (GAC, $500 \mathrm{mg} / \mathrm{l} ;\left[\mathrm{H}_{2} \mathrm{O}_{2}\right]_{0}, 20 \mathrm{mM}$; temperature, $30{ }^{\circ} \mathrm{C}$; ionic strength, $50 \mathrm{mM} \mathrm{NaClO}$ ).

Substances that adsorbed to aquifer sand surface could affect the degradation of $\mathrm{H}_{2} \mathrm{O}_{2}$ and organics (Miller and Valentine, 1995; Valentine and Wang, 1998). To examine the role of adsorption in the oxidation experiment, the relationship between the total reduction of 4-CP and DOC (dissolved organic carbon) in suspension is shown in Fig. 5. The decrease of DOC could be attributed to the advanced adsorption of 4-CP and its oxidation intermediates. The loss of DOC caused from the mineralization could be ignored for the weak catalytic activity toward the destruction of 4-CP in this system. For GAC1 and GAC2, the decrease of DOC is

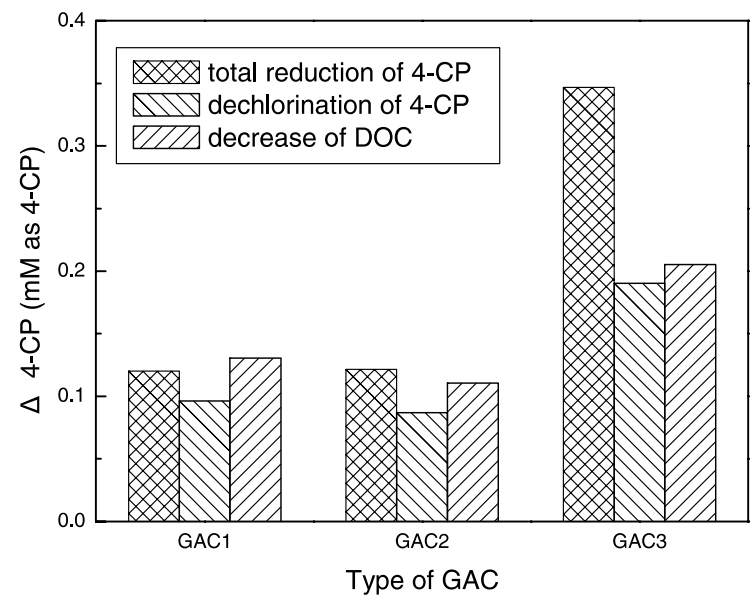

Fig. 5. Total change of 4-CP and DOC in presence of activated carbons $\left(\mathrm{GAC}, 500 \mathrm{mg} / \mathrm{l} ;\left[\mathrm{H}_{2} \mathrm{O}_{2}\right]_{0}, 20 \mathrm{mM}\right.$; temperature, $30{ }^{\circ} \mathrm{C}$; ionic strength, $50 \mathrm{mM} \mathrm{NaClO}$ ). similar to the total reduction of 4-CP, indicating that 4$\mathrm{CP}$ and its oxidation intermediates are almost adsorbed further onto GAC surface. However, GAC3 shows a stronger catalytic activity but weaker adsorption capacity toward 4-CP and its oxidation intermediates. The adsorption capacity of activated carbon toward phenolic compounds would be enhanced as the adsorption isotherm conducted in an oxic condition, i.e. oxidative coupling adsorption (Vidic et al., 1993). Therefore, the oxygen produced from $\mathrm{H}_{2} \mathrm{O}_{2}$ decomposition in oxidation experiment would increase the adsorption capacity of activated carbon even the real adsorption equilibrium had been achieved. The portion of adsorption caused from different substances is difficult to be divided. However, for the data of GAC3, even the decrease of DOC is entirely contributed from the oxidative-coupling adsorption, the total reduction of 4-CP is still much larger than that of DOC, indicating that the catalyzed degradation of 4-CP did occur in this system. In addition, no matter the reduction of 4-CP is attributed to the oxidative adsorption or catalytic oxidation, the combination of $\mathrm{H}_{2} \mathrm{O}_{2}$ and $\mathrm{GAC}$ has increased the reduction of 4-CP than that contributed by single GAC adsorption.

To explain why the three modified activated carbons exhibited different catalytic activity toward 4-CP oxidation, a general simplified mechanism proposed to describe the catalyzed organics with $\mathrm{H}_{2} \mathrm{O}_{2}$ is quoted as (Miller and Valentine, 1995)

$\mathrm{H}_{2} \mathrm{O}_{2} \stackrel{k_{1, \text { surface }}}{\longrightarrow} I \stackrel{k_{2, \text { surface }}}{\longrightarrow} \mathrm{O}_{2}+\mathrm{H}_{2} \mathrm{O}$

$I+$ Organics $\stackrel{k_{1, \text { solution }}}{\longrightarrow}$ Products

where $I$ is intermediate (e.g. ' $\mathrm{OH}$ or $\mathrm{O}_{2}^{-}$) produced from the reaction of $\mathrm{H}_{2} \mathrm{O}_{2}$ with catalyst surface, $k_{1, \text { surface }}$ and $k_{2, \text { surface }}$ are the surface rate constants, and $k_{3, \text { solution }}$ is the rate constant in the reaction solution. In this study, the catalytic activity toward 4-CP loss is corresponded to the inverse sequence of that toward $\mathrm{H}_{2} \mathrm{O}_{2}$ decomposition for the three activated carbons. This phenomenon implies that the decrease of catalytic activity available for $\mathrm{H}_{2} \mathrm{O}_{2}$ (i.e. $k_{1 \text {,surface }}$ ) by the oxidizing treatment would also reduce the surface activity $\left(k_{2, \text { surface }}\right)$ to scavenge the intermediates of $\mathrm{H}_{2} \mathrm{O}_{2}$, and then induce to increase the collision probability for the effective radicals and organics (e.g. 4-CP). As discussed in $\mathrm{H}_{2} \mathrm{O}_{2}$ decomposition earlier, it could be concluded that the acidic functional groups would decrease the catalytic activity toward $\mathrm{H}_{2} \mathrm{O}_{2}$ and its intermediates but increase the degradation efficiency of 4-CP. Miller and Valentine (1995) found that the modified aquifer sand by acid-hydroxylamine decreased the rate of $\mathrm{H}_{2} \mathrm{O}_{2}$ decay while increased the degradation efficiency of quinoline significantly. Lin and Lai (2000) suggested an adsorption/ozonation mechanism that the destruction of organic was not only due to 
Table 5

The comparison of dechlorination efficiency for each sequential $\mathrm{H}_{2} \mathrm{O}_{2}$ dosage

\begin{tabular}{llllll}
\hline Parameter & GAC1 $(20 \mathrm{mM})$ & GAC2 $(20 \mathrm{mM})$ & GAC3 $(20 \mathrm{mM})$ & GAC3 $(15 \mathrm{mM})$ & GAC3 $(10 \mathrm{mM})$ \\
\hline$E_{\mathrm{D} 1}\left(\times 10^{2}\right)$ & 0.38 & 0.35 & 1.26 & 1.11 & 1.29 \\
$E_{\mathrm{D} 2}\left(\times 10^{2}\right)$ & 0.32 & 0.32 & 1.65 & 1.11 & 1.06 \\
$E_{\mathrm{D} 3}\left(\times 10^{2}\right)$ & 0.24 & 0.32 & 1.41 & 2.59 & 2.09 \\
Average $\left(\times 10^{2}\right)$ & 0.31 & 0.33 & 1.44 & 1.60 & 1.47 \\
pH range & $5.6-3.9$ & $4.9-3.6$ & $3.9-3.3$ & $3.8-3.2$ & $3.9-3.4$ \\
\hline
\end{tabular}

Catalyst dosage $=500 \mathrm{mg} / \mathrm{l} ; E_{\mathrm{D} 1,2,3}$ is the ratio of 4-CP loss to $\mathrm{H}_{2} \mathrm{O}_{2}$ loss in each $\mathrm{H}_{2} \mathrm{O}_{2}$ dosage.

the direct ozonation but also the adsorbed pollutant oxidized catalytically on GAC surface.

Some additional results conducted with various activated carbons and $\mathrm{H}_{2} \mathrm{O}_{2}$ concentrations are shown in Table 5. A similar average efficiency for the different addition of $\mathrm{H}_{2} \mathrm{O}_{2}$ concentrations $(10-20 \mathrm{mM})$ is observed, indicating that the degradation efficiency of 4-CP is independent of the $\mathrm{H}_{2} \mathrm{O}_{2}$ concentration for the same starting 4-CP concentration. Furthermore, according to the mechanism (Eq. (6)), it is plausible that the degradation efficiency of 4-CP should be the function of 4-CP concentration. If the 4-CP concentration in aqueous phase would affect the degradation efficiency, the decrease of efficiency should occur because of the decrease in 4-CP concentration at the time of each $\mathrm{H}_{2} \mathrm{O}_{2}$ addition during oxidation experiment. No obvious declining trend of dechlorination efficiency (i.e. $E_{\mathrm{D} 1,2,3}$ ) is observed for each $\mathrm{H}_{2} \mathrm{O}_{2}$ dosage in Table 5. The effect of $\mathrm{pH}$ should be taken into consideration. The variance of $\mathrm{pH}$ in oxidation experiment for GAC1 and GAC2 is larger than unit which could affect the degradation efficiency. However, with a small variance of $\mathrm{pH}$, the effect of $\mathrm{pH}$ on degradation efficiency could be ignored in the presence of GAC3. Therefore, it could be concluded that the degradation efficiency toward 4-CP for GAC3 is independent of 4-CP amount remaining in aqueous phase. This unexpected result could be attributed to the excess concentration of 4-CP in comparison with the relative small amount of effective radicals which is consistent with the low oxidation rate of 4-CP observed in this study.

\section{Conclusions}

The modified surface property of the GAC by oxidizing agent indeed affect not only the decomposition of $\mathrm{H}_{2} \mathrm{O}_{2}$ but also the oxidation of 4-CP significantly. The catalytic activity toward $\mathrm{H}_{2} \mathrm{O}_{2}$ follows an increased sequence of $\mathrm{pH}_{\mathrm{pzc}}$ for the three activated carbons. The decomposition kinetics of $\mathrm{H}_{2} \mathrm{O}_{2}$ over GAC can be well described by the $\mathrm{L}-\mathrm{H}$ rate model. The rate constant increases with the increase of equilibrium constant $\left(k_{\mathrm{H}}\right)$, indicating the binding of $\mathrm{H}_{2} \mathrm{O}_{2}$ on the surface of catalyst could be an important factor on $\mathrm{H}_{2} \mathrm{O}_{2}$ decomposition.
In comparison with the mass transfer rate, the reaction rate of $\mathrm{H}_{2} \mathrm{O}_{2}$ decomposition is mainly dominated by the surface reaction. The acidic functional group may play a major role in this catalytic oxidation system, which would decrease the catalytic activity toward $\mathrm{H}_{2} \mathrm{O}_{2}$ and its intermediates inducing the increase of the 4-CP degradation efficiency. The degradation efficiency of 4-CP is independent of the initial $\mathrm{H}_{2} \mathrm{O}_{2}$ concentration, but the amount of 4-CP lost is proportional to the decomposition of $\mathrm{H}_{2} \mathrm{O}_{2}$. The efficiency relating 4-CP loss and $\mathrm{H}_{2} \mathrm{O}_{2}$ decay is independent of 4-CP concentration, which could be attributed to the small amount of effective radicals. The degradation efficiency of 4-CP for the modified activated carbon is comparable to those of the other oxidation systems using metal oxides as catalyst, suggesting an attractive alternative for the removal of organic pollutant in wastewater treatment.

\section{Acknowledgements}

This research was supported by the National Science Council, Republic of China (Grant NSC 90-2211-E-041014).

\section{References}

Castilla, C.M., Ferro-Garcia, M.A., Joly, J.P., 1995. Activated carbon surface modifications by nitric acid, hydrogen peroxide, and ammonium peroxydisulfate treatments. Langmuir 11 (11), 4386-4392.

Chou, S., Huang, C., 1999. Application of a supported iron oxyhydroxide catalyst in oxidation of benzoic acid by hydrogen peroxide. Chemosphere 38 (12), 2719-2731.

Figueiredo, J.L., Pereira, M.F.R., Freitas, M.M.A., 1999. Modification of the surface chemistry of activated carbons. Carbon 37 (9), 1379-1389.

Francisco, R.R., 1998. Plenary lecture: the role of carbon materials in heterogeneous catalysis. Carbon 36 (3), 159175.

Heisig, C., Zhang, W., Oyama, T., 1997. Decomposition of ozone using carbon-supported metal oxide catalysts. Applied Catalysis B: Environmental 14 (1-2), 117-129.

Huang, H.H., Lu, M.C., Chen, J.N., 2001. Catalytic decomposition of hydrogen peroxide and 2-chlorophenol with iron oxides. Water Research 35 (9), 2291-2299. 
Khalil, L.B., Girgis, B.S., Tawfik, T.A., 2001. Decomposition of $\mathrm{H}_{2} \mathrm{O}_{2}$ on activated carbon obtained from olive stones. Journal of Chemical Technology and Biotechnology 76 (11), 1132-1140.

Kong, S.H., Watts, R.J., Choi, J.H., 1998. Treatment of petroleum-contaminated soils using iron mineral catalyzed hydrogen peroxide. Chemosphere 37 (8), 1473-1482.

Lin, S.S., Gurol, M.D., 1998. Catalytic decomposition of hydrogen peroxide of iron oxide: kinetics, mechanism, and implications. Environmental Science and Technology 32 (10), 1417-1423.

Lin, S.H., Lai, C.L., 2000. Kinetic characteristics of textile wastewater ozonation in fluidized and fixed activated carbon beds. Water Research 34 (3), 763-772.

Lu, M.C., Chen, J.N., Huang, H.H., 2002. Role of goethite dissolution in the oxidation of 2-chlorophenol with hydrogen peroxide. Chemosphere 46 (1), 131-136.

Lucking, F., Koser, H., Jank, M., Ritter, A., 1998. Iron powder, graphite and activated carbon as catalysts for the oxidation of 4-chlorophenol with hydrogen peroxide in aqueous solution. Water Research 32 (9), 2607-2614.

Miller, C.M., Valentine, R.L., 1995. Hydrogen peroxide decomposition and quinoline degradation in the presence of aquifer material. Water Research 29 (10), 2353-2359.

Miller, C.M., Valentine, R.L., 1999. Mechanistic studies of surface catalyzed $\mathrm{H}_{2} \mathrm{O}_{2}$ decomposition and contaminant degradation in the presence of sand. Water Research 33 (12), 2805-2816.

Noh, J.S., Schwarz, J.A., 1989. Estimation of the point of zero charge of simple oxides by mass titration. Journal of Colloid and Interface Science 130 (1), 157-164.

Ravikumar, J.X., Gurol, M.D., 1994. Chemical oxidation of chlorinated organics by hydrogen peroxide in the presence of sand. Environmental Science and Technology 28 (3), 394-400.

Satterfield, C.N., 1981. Mass Transfer in Heterogeneous Catalysis. Robert E. Krieger Publishers, Florida.

Schumb, W.E., Satterfield, C.N., Wentworth, R.L., 1955. Hydrogen Peroxide. Chapman \& Hall Ltd., London.

Stumm, W., 1992. Chemistry of the Solid-Water Interface. Wiley-Interscience Publication, New York.

Tessmer, C.H., Vidic, R.D., Uranowski, L.J., 1997. Impact of oxygen-containing surface functional groups on activated carbon adsorption of phenols. Environmental Science and Technology 31 (7), 1872-1878.

Valentine, R.L., Wang, H.C.A., 1998. Iron oxide surface catalyzed oxidation of quinoline by hydrogen peroxide. Journal of Environmental Engineering 124 (1), 31-38.

Vidic, R.D., Suidan, M.T., Brenner, R.C., 1993. Oxidative coupling of phenols on activated carbon: impact on adsorption equilibrium. Environmental Science and Technology 27 (10), 2079-2085. 